\title{
Competitividad y excelencia académica en Medicina
}
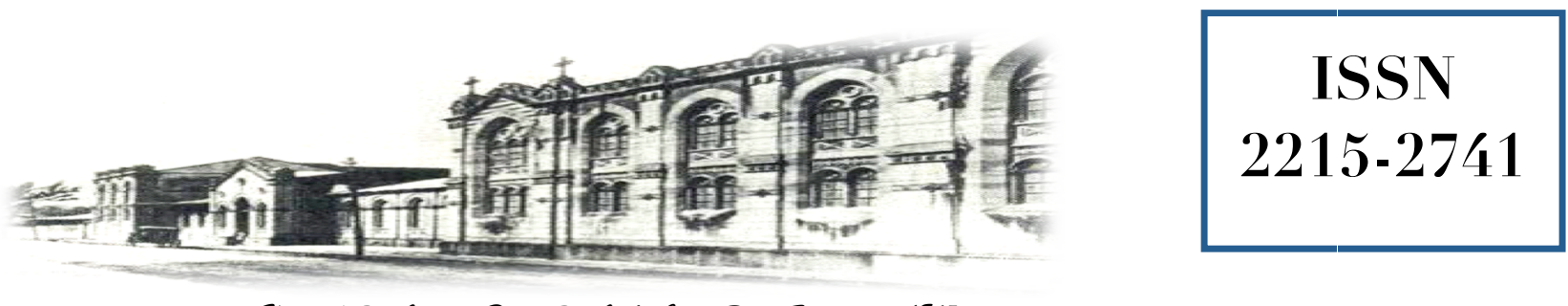

Haspital San quan de Dias, San José. Casta Rica. Fundado en 1845

$\begin{array}{ll}\text { Recibido: } & 20 / 11 / 2014 \\ \text { Aceptado: } & 19 / 02 / 2014\end{array}$

Luis Fernando Briceño Rodríguez ${ }^{1}$

${ }^{\mathbf{1} E x-M i e m b r o}$ Sección de Medicina - Hospital San Juan de Dios. Profesor Asociado Universidad de Costa Rica (pensionado). Correo electrónico: lbriceno@racsa.co.cr

En la actualidad existen en Costa Rica varias Escuelas de Medicina que han surgido, al igual que en otras áreas profesionales, de una manera privada; un fenómeno natural en un país en vías de desarrollo, así como en las naciones desarrolladas.

La "competencia" siempre es buena, ya que nos impulsa a la superación.

La calidad de un profesional se vislumbra desde su temprana época de estudiante universitario. Es acá donde se conoce quien es bueno o regular; por lo cual, se debe aprender a competir por ser los mejores, pero fundamentalmente de una forma leal y honesta.

La calidad académica de los egresados de una Escuela de Medicina está en manos de la Escuela misma, de sus docentes y de sus estudiantes. Es una obligación de los profesores dar una adecuada orientación, $y$ es un deber del estudiantado aprovechar al máximo la información y formación que recibe.
Por la naturaleza de nuestra profesión, todo estudiante de pregrado, grado y posgrado debe asimilar de la mejor manera los conocimientos, destrezas y conceptos fundamentales de la Medicina, con disciplina, ambición y perseverancia; pero ante todo, con verdadera vocación. Se debe tener un deseo grande de estudio continuo, porque nunca terminamos de aprender algo nuevo. Cada tópico a revisar e investigar, debe comprenderse en el buen sentido de la palabra, con una mentalidad receptiva y crítica. Con el paso del tiempo, el único beneficiado es el estudiante mismo.

El docente universitario que recibe estudiantes a nivel clínico, observa que lo importante es la calidad y actitud del estudiante. Hay buenos, regulares y en una minoría algunos malos estudiantes. Habrá pocos que sean conformistas con la nota mínima aprobatoria, lo cual es muy doloroso.

Qué estimulante es encontrar a aquellas personas que desean superarse y mostrar como estudiantes ese deseo propio de superación; el deseo de ser 
buenos profesionales, de querer ser los mejores; de sobresalir ante los demás únicamente por capacidad académica; y esto es algo que se logrará si se proponen hacerlo. No deben existir límites para que algún estudiante no alcance con excelencia sus metas, pero esto en todo caso demandará tenacidad y esfuerzo.

Es por ello importante que exista la "competencia". "Competencia" entre nuestros estudiantes y también "competencia" entre nuestra Escuela con las otras Escuelas de Medicina del país.

El estudiante debe prepararse para llegar a ejercer su profesión en un campo muy competitivo, y estar capacitado para actuar con excelencia a cualquier nivel, en nuestro medio nacional y más allá de nuestras fronteras, con calidad y con amor por lo que hace.

El profesorado de nuestra Escuela, debe dar el máximo de sí mismo, tanto durante la docencia directa, como en la docencia tutorial. En la primera, deben mantener actualizadas sus lecciones, y no sólo dedicarse a impartir información que el estudiante podría obtener de los libros y revistas científicas impresas o digitales. Sino orientar a sus alumnos en la comprensión de los diferentes temas que está impartiendo. La docencia tutorial debe ser muy dinámica, para alcanzar el máximo de provecho por parte de los estudiantes; no debiéndose limitar únicamente a las pasadas de visita magistrales, sino convertir la actividad en una enseñanza-aprendizaje bidireccional: profesorestudiante, estudiante-profesor, con análisis de cada dato y observación obtenidas de los enfermos, con cuestionamientos y planteamientos que ayuden a encontrar al educando la formación correcta de la práctica clínica y científica. Debemos prepararnos a ser los mejores.

La Escuela de Medicina debe estimular a los profesores a ejercer la docencia con entusiasmo, no permitiendo "la fuga" de excelentes médicos. Debe favorecer la buena preparación académica y científica de sus docentes.

La presencia de otras universidades genera un importante número de médicos y futuros médicos, que también luchan y lucharán por un mercado laboral.
La competencia hará sobresalir a los mejores, a aquellos que se esfuerzan.

No debe existir ningún temor a la "competencia" objetiva y leal. Estamos seguros de la calidad de formación de los egresados de la Escuela de Medicina de nuestra querida Universidad, porque la "competencia" genera excelencia.

Al igual que en el pasado y en el presente, los resultados continuarán estando en nuestras manos, la Escuela de Medicina, los profesores y los estudiantes, "todos en uno"; porque la superación académica y profesional son fundamentales en el ejercicio de la Medicina.

Debemos ir siempre a la vanguardia de los cambios en el futuro de la Medicina nacional.

Basado, actualizado y modificado de: Briceño R, LF. Competitividad en la Medicina. Práctica Médica 1997; 2 (3): 3.

(Autorización por Dr. Chi Hao Chen Ku - Cuerpo Editorial Revista Práctica Médica 1997) 